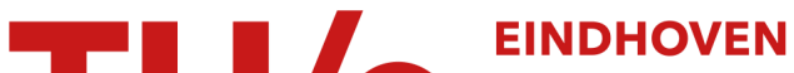 UNIVERSITY OF TECHNOLOGY
}

\section{Measuring time-dependent mechanics in metallic MEMS}

\section{Citation for published version (APA):}

Bergers, L. I. J. C., Delhey, N. K. R., Hoefnagels, J. P. M., \& Geers, M. G. D. (2010). Measuring time-dependent mechanics in metallic MEMS. In L. J. Ernst, G. Q. Zhang, W. D. Driel, P. Rodgers, C. Bailey, \& O. De Saint leger (Eds.), Proceedings of the 11th International Conference on Thermal, Mechanical and Multiphysics Simulation and Experiments in Micro-Electronics and Micro-Systems (EuroSimE 2010), 26-28 April 2010, Linz, Austria (pp. 1-6). Institute of Electrical and Electronics Engineers. https://doi.org/10.1109/ESIME.2010.5464590

DOI:

10.1109/ESIME.2010.5464590

Document status and date:

Published: 01/01/2010

\section{Document Version:}

Accepted manuscript including changes made at the peer-review stage

\section{Please check the document version of this publication:}

- A submitted manuscript is the version of the article upon submission and before peer-review. There can be important differences between the submitted version and the official published version of record. People interested in the research are advised to contact the author for the final version of the publication, or visit the $\mathrm{DOI}$ to the publisher's website.

- The final author version and the galley proof are versions of the publication after peer review.

- The final published version features the final layout of the paper including the volume, issue and page numbers.

Link to publication

\section{General rights}

Copyright and moral rights for the publications made accessible in the public portal are retained by the authors and/or other copyright owners and it is a condition of accessing publications that users recognise and abide by the legal requirements associated with these rights.

- Users may download and print one copy of any publication from the public portal for the purpose of private study or research.

- You may not further distribute the material or use it for any profit-making activity or commercial gain

- You may freely distribute the URL identifying the publication in the public portal.

If the publication is distributed under the terms of Article 25fa of the Dutch Copyright Act, indicated by the "Taverne" license above, please follow below link for the End User Agreement:

www.tue.nl/taverne

Take down policy

If you believe that this document breaches copyright please contact us at:

openaccess@tue.nl

providing details and we will investigate your claim. 


\title{
Measuring time-dependent mechanics in metallic MEMS
}

\author{
L.I.J.C.Bergers, N.K.R.Delhey, J.P.M.Hoefnagels, M.G.D.Geers \\ Eindhoven University of Technology, Dep. of Mechanical Engineering \\ P.O. Box 513, 5600 MB, Eindhoven, The Netherlands \\ L.I.J.C.Bergers@tue.nl
}

\begin{abstract}
The reliability of metallic microelectromechanical systems (MEMS) depends on time-dependent deformation such as creep. The interaction between microstructural length scales and dimensional length scales, so-called 'size-effects', play a prominent role in this. As a first critical step towards studying these size effects in time-dependent deformation, a purely mechanical experimental methodology has been developed, which is discussed here. It is found most suitable for the investigation of creep due to the simplicity of sample handling and preparation and setup design, whilst maximizing long term stability and displacement resolution. The methodology entails the application of a constant deflection to a $\mu \mathrm{m}$-sized free-standing aluminum cantilever beam for a prolonged period of time. After this load is removed, the deformation evolution is immediately recorded by acquiring surface height profiles through confocal optical profilometry. Image correlation and an algorithm based on elastic beam theory are applied to the full-field beam profiles to yield the tip deflection as function of time. From a discussion on the sources of experimental error, it is concluded that the methodology yields the tip deflection as function of time with $\sim 3 \mathrm{~nm}$ precision.
\end{abstract}

\section{Reliability and time-dependent mechanics}

The application of metals as structural components in MEMS is common for 'radio-frequency MEMS' (RFMEMS). Figure 1 shows an example. The reliability of these devices has been shown to critically depend on time-dependent mechanics, such as fatigue and creep [1]. Fatigue affects the device life time through its limitation on the number of device operation cycles, e.g. the number of open/closed cycles of an RF-MEMS switch. Creep can directly affect the operational characteristic, e.g. through a shift in pull-in voltage of an RF-MEMS switch which results in a reduced power handling [2]. Whereas fatigue effects may pose less of a problem than expected at small geometrical length scales [3], the detrimental influence of creep seems to increase upon miniaturization [3].

The difference between micro- and macroscale creep is generally attributed to the size-effect: the interaction between microstructural length scales and dimensional length scales [4;5]. The physical micro-mechanisms of creep are, however, not nearly understood, let alone implemented in models. Specifically for free-standing thin films not much research has focused on characterizing size-effects in time-dependent material behavior [6]. Modlinski et.al. demonstrated that a carefully-chosen alloy can suppress creep effects in Al- alloys used in RF-MEMS [7;8], However, besides qualitative observations of the effect of dispersion density of precipitates, other size-effects were not investigated. Therefore, there is a clear need for detailed studies into the physical micro-mechanisms underlying the sizeeffects in creep in metallic MEMS.

As a first step towards such studies, the goal of the current work is to construct and validate an experimental mechanical methodology to quantify creep, of $\mu \mathrm{m}$-sized free-standing cantilever beams. To this end, first the factors are discussed that determine the choices for the design of the experiment, followed by the explanation of the methodology. Next, proof-of-principle measurements are conducted and the results are presented together with a critical discussion of the precision of the methodology. To this end, the influence of each step on the precision is evaluated, where possible quantitatively. Finally, conclusions are drawn with respect to the goal of this work and the further application of this work to the study of size-effects in creep in metallic-MEMS.

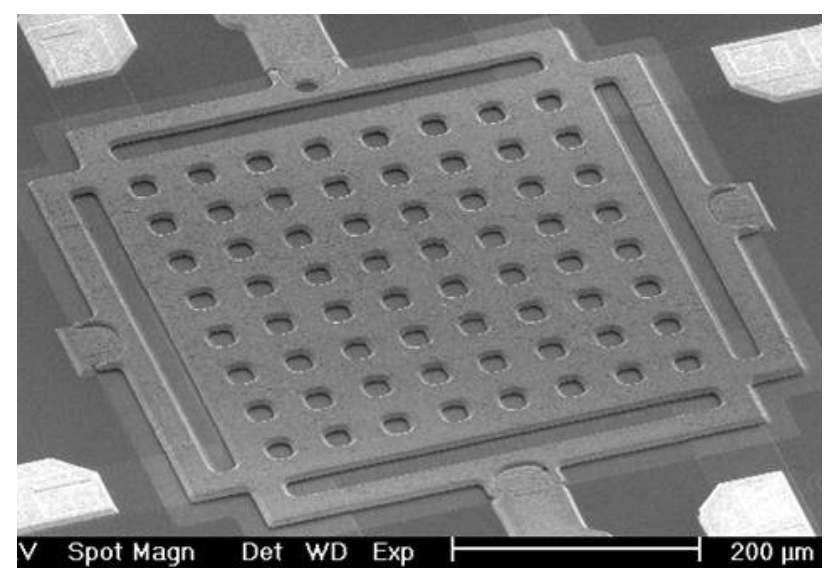

Figure 1: Scanning electron microscopy image of an $R F$ MEMS switch (courtesy of EPCOS Netherlands B.V.).

\section{Experimental design}

Performing mechanical tests on specimens that are free-standing and have dimensions in the order of $\mu \mathrm{m}$ is not trivial. Aspects of sample preparation, handling, loading, load and deformation measurement and control have to be carefully addressed [9]. Considering the sample preparation and handling, it is highly preferred to test free-standing, micron scale on-wafer samples that have been fabricated in the same micro-fabrication process as that of the actual MEMS device. This simplifies the handling of $\mu \mathrm{m}$ sized samples to handling $20 \times 20 \mathrm{~mm}^{2}$ dies/wafer pieces. It also guarantees that the results obtained in an experiment are fully applicable to the corresponding MEMS device. A critical aspect of the 
load and displacement control and measurement is the long term stability especially for prolonged creep measurements. Therefore, a small and simple displacement controlling mechanism is most suitable. A so-called 'micro-clamp' is designed, which is a simple horizontal knife-edge attached to an elastic hinge, see Figure 2. The height of the edge with respect to the substrate is controlled to $\sim 50 \mathrm{~nm}$ via a differential screw. Drift due to temperature and electrical effects are minimized by a compact and near-monolithic fully mechanical design. In-plane placement is achieved with $\sim 5 \mu \mathrm{m}$ resolution using an adjustment screw. To measure the out-of-plane deformation optical confocal profilometry is employed. This yields full-field deformation information, with 10-nm RMS repeatability for a high magnification super long working distance objective. Interferometric profilometry is not suited to deal with the combination of a large working distance (mm's) imposed by the micro-clamp and the large local surface angles associated with the relatively high surface roughness of the metallic MEMS considered here. The measurement precision will benefit from the full-field deformation combined with simple image processing and beam-bending equations. Another advantage of this methodology is that multiple samples can be deflected in parallel simply by aligning all samples on the chip and using a broad knife-edge. Furthermore the setup does not involve any highly specialised parts or instruments which allows for easy and inexpensive parrallelization. This is particularly usefull for prolonged creep experiments.. The only drawback is the lack of a direct measurement of force. Given the mentioned benefits of this methodology, i.e. simplicity, long term stability, deflection resolution, it is found most suitable.

Based on these considerations, the choice has been made to design an experiment measuring the timedependent deflection recovery of a cantilever after constant deflection. Figure 3 shows the deflection sequence. The initial deflection is controlled by the 'micro-clamp'. Directly after release of the deflection, a time series of full-field deformation maps is measured with a commercial confocal optical profilometer. An algorithm based on elastic beam theory is than applied to the deformation data to extract the evolution of the deflection as function of time. This methodology thus allows simple sample handling and MEMS-device fabrication, and precise control and measurement of the deformation over a longer period of time.

\section{Experimental method}

The deflection of the microbeam test structure is controlled by the micro-clamp. This is done under the optical profilometer, a Sensofar Plu2300. The surface profilometer is operated in the confocal microscopy mode: $470 \mathrm{~nm}$ LED light, 100x long working distance objective with N.A. of 0.7 , height of scan of $20 \mu \mathrm{m}$, data acquisition time $\sim 85 \mathrm{~s}$. In this configuration, the RMS repeatability is $<10 \mathrm{~nm}$, although data acquisition and processing will improve the overall precision. Finally, the (optically flat) substrate is leveled to within $0.01^{\circ}$ by using the interferometric mode of the optical profilometer and manually adjusting a 2-axis tilt stage. The setup is stabilized on an active vibration isolation table. The measurements are conducted in an environmentally controlled room, with $\mathrm{T}_{\text {ambient }}=21.0 \pm 1.0{ }^{\circ} \mathrm{C}, \mathrm{RH} 14 \pm 1 \%$.

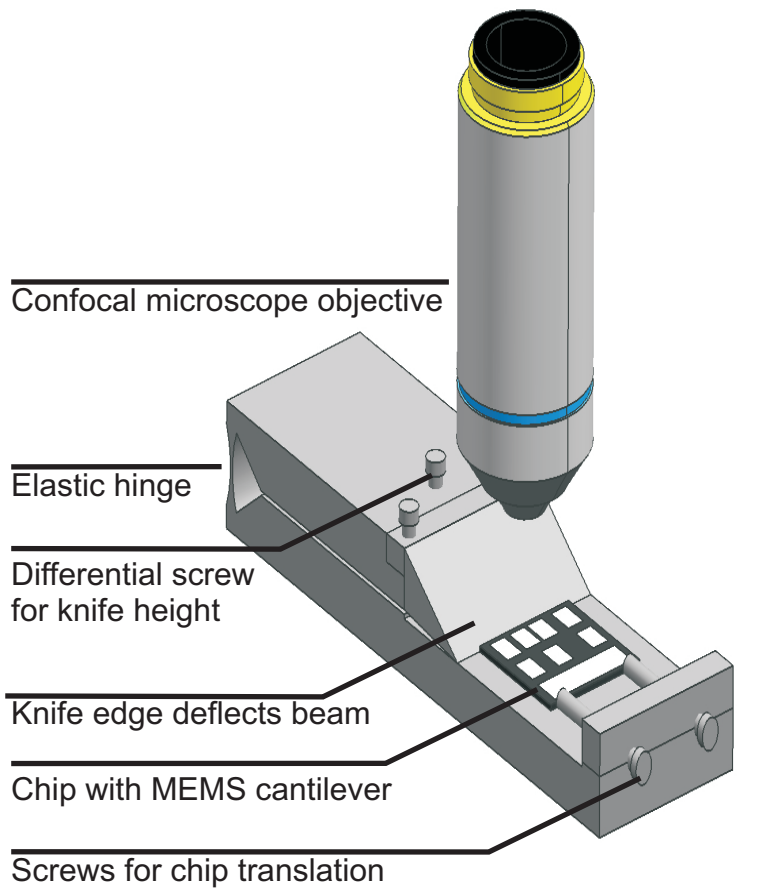

Figure 2: Schematic of the MEMS cantilever deflection experiment with a micro-clamp under a confocal optical profilometer, which captures the deflection as function of time.

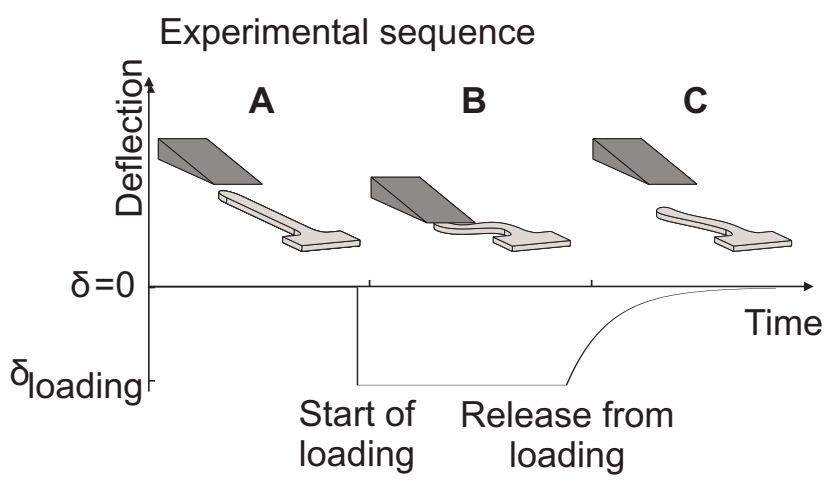

Figure 3: Schematic representation of the measurement sequence of the cantilever deflection recovery experiment. (A) The knife-edge of the micro-clamp approaches the cantilever. (B) The knife-edge deflects the cantilever to a depth of $\delta_{\text {loading }}$ and holds it there for a certain period of time. (C) The edge is raised, releasing the cantilever, after which the deflection recovery is measured over time using a surface profilometer.

Figure 4 shows an example of the cantilever beam test structures investigated here. The beams are produced from $\mathrm{Al}-\mathrm{Cu}(1 \mathrm{wt} \%)$ on a test-wafer having undergone a production process scheme as used for actual RF-MEMS switches. The Young's modulus is $66.8 \mathrm{GPa}$, determined by eigenfrequency measurements and finite element analysis of electro-statically actuated cantilevers [10;11]. 
The film thickness is $4.8 \pm 0.2 \mu \mathrm{m}$ and has a surface roughness $R_{A}=45 \mathrm{~nm}$. The film consists of columnar, through-thickness grains with $\{111\}$ surface orientation and an average grain diameter of $20 \mu \mathrm{m}$, assuming cylindrical grain shapes, as determined with electron backscatter diffraction. Several beams having a width of $25 \mu \mathrm{m}$ and lengths between 45 and $500 \mu \mathrm{m}$ are on the test-wafer. Cross-sections are trapezoidal due to the thin film patterning. This work employs a beam of $65 \mu \mathrm{m}$ length. This choice is a trade-off between practical imaging, deflection and induced stress levels.

The experiment is conducted as follows. The wafer is placed on the micro clamp and the beam is aligned to the knife-edge (with $\sim 5 \mu \mathrm{m}$ lateral precision) under the microscope. Leveling (to within $0.01^{\circ}$ ) is conducted with interferometry. A surface topography of the unaltered beam (reference height position) is acquired in the confocal profilometer mode, see the top left of Figure 5. The knife edge is then lowered to deflect the beam to a depth of approximately $800 \mathrm{~nm}$ (much less that the microbeam-substrate gap), see the top right of Figure 5. This level is chosen as it corresponds to $\sigma_{\text {bend,max }}=50 \mathrm{MPa}$ for this length. This stress level corresponds to $\sim 30 \%$ of the yield stress of the material and is a lower level encountered in RF-MEMS device operation. The beam is then kept deflected at this position for 48 hours, after which the unloading procedure is started. The edge knife is raised and immediately thereafter, at every $85 \mathrm{~s}$, surface topographies are obtained for 10000s. Finally images are taken every 900 s for another $10000 \mathrm{~s}$. The bottom of Figure 5 shows an example of one of the obtained surface topographies.

In this manner a set of surface profiles is obtained of the recovering deformation in the beam. The surface profiles do not immediately yield the tip deflection as function of time. Data processing is required to deal with image translations and tilt due to thermal and various other drifts in the optical profilometry set-up. A simple self-programmed image correlation algorithm that mainly aligns the test structure edges is implemented in software package Matlab to compensate for $\mathrm{x}$ and $\mathrm{y}$ translations with pixel-resolution. It is confirmed that rotations around the axis-perpendicular to the surface can be neglected. Tilt around $\mathrm{x}$ or $\mathrm{y}$-axis are dealt with by applying a linear leveling algorithm, using the double clamped plate as reference, see Figure 6 . It will be shown further on that the deformation at the part of the plate used as a reference for leveling falls well within the measurement precision, thus validating this choice for leveling.

The tip deflection is determined by fitting standard beam bending theory to the full-field deformation data of the beam. This uses the intrinsic assumptions that the bending is elastic and that the double clamped plate effectively fixes the beam. Figure 6 shows schematically how area bins $\left(16 \times 1 \mu \mathrm{m}^{2}\right)$ are created along the length of the beam and plate in which the surface height is averaged. This minimizes the height measurement error. A region on the clamped plate is selected as reference height from which the beam deflection is determined. Subsequently the equation for a single clamped beam is fit to the profile.
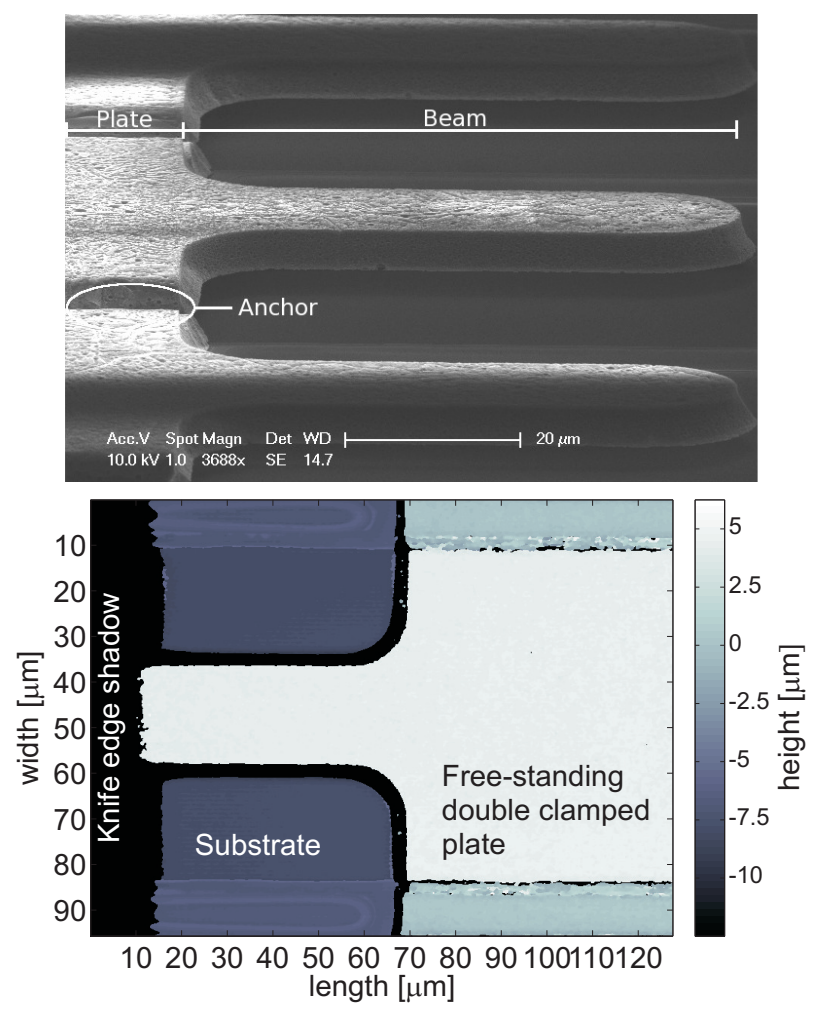

Figure 4: (Top) A SEM-image of a test cantilever beam that is attached to a free-standing plate clamped on three sides by an anchor. (Bottom) A contour map of a profile of a beam placed under the micro-clamp obtained with confocal profilometry.

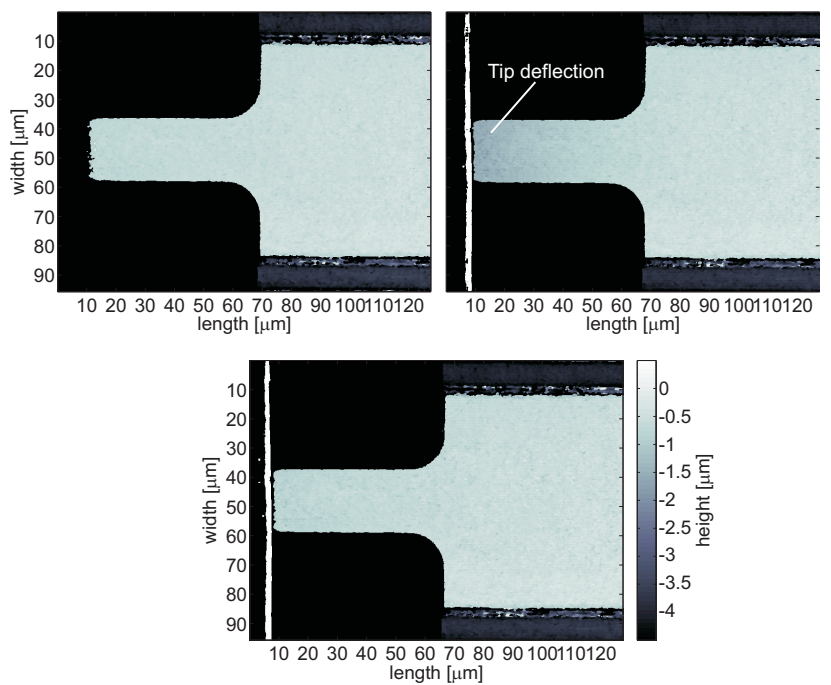

Figure 5: Surface profiles of Al-beams before (top left), during (top right) and after (bottom) deflection with knife edge. During and after loading, the micro-clamp is low enough to appear in the height profile as a white line. Note that the scale is adjusted to visualize tip deflection. 


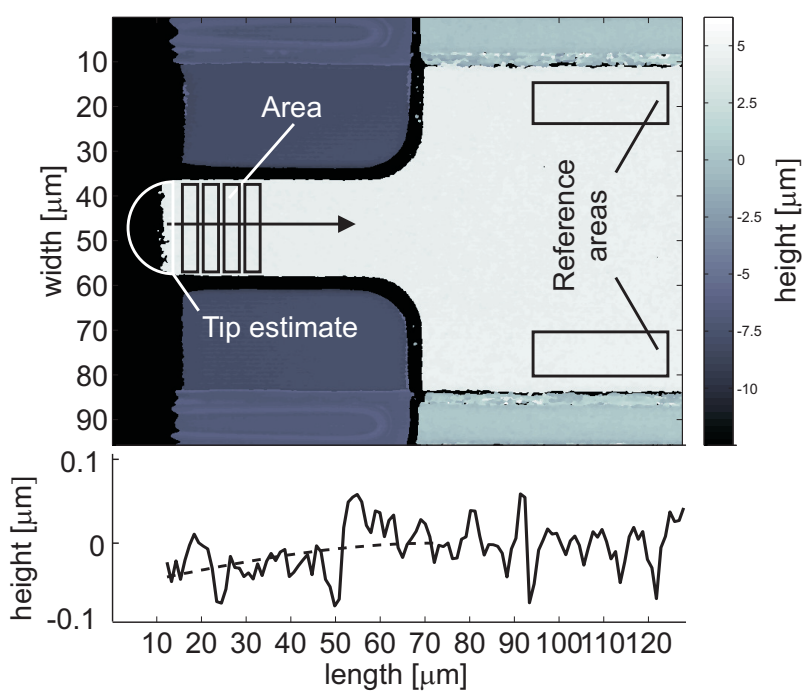

Figure 6: Surface profile schematically illustrating the area bins and selected reference areas, all of which are schematically drawn here for clarification purpose. The mean height of these boxed areas is evaluated to form a profile. Linear plane fitting is applied based on the reference areas to correct for tilt around $x$ and $y$ axis. These areas are then used as reference height and set to zero height. The profiles are referenced to this height. Standard beam bending equations are fit to the profile as indicated by the dashed line in the lower graph. For clarification, a semi-circle is drawn at the location of the tip.

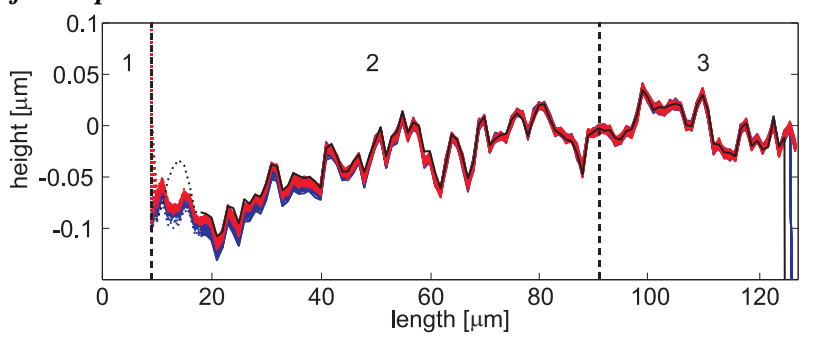

Figure 7: Results of the obtained profiles after deflection at $\sim 800 \mathrm{~nm}$ for a duration of $\sim 48$ hours. Note that the surface roughness of the metallic MEMS is much higher than the change in tip deflection, which is of interest. The initial profile (acquired before any deflection) is plotted in black. The first profile acquired after unloading is plotted in blue and subsequent profiles are plotted with a gradient from blue to red. The dotted lines represent unreliable data, as the microclamp is partially blocking the reflection of light. Three sections are distinguished: (1) the micro-clamp, (2) the profile of the beam, and (3) the reference height.

\section{Experimental results}

The result of the measured deflection recovery is a sequence of profiles, seen in Figure 7, from which the tip deflection as a function of time is determined, as shown in Figure 8. After an instantaneous initial spring back of more than $95 \%$ of the loading depth, the beam shows a relatively small, though clear monotonous increase in height of $\sim 20 \mathrm{~nm}$ over a time period of about 3 hours. This is evidence of time-dependent recovery of the cantilever. Next to this, a permanent deflection of $\sim 10 \mathrm{~nm}$ is observed. To asses the precision of the measurement a fit is made to the tail of the graph where the deflection has saturated. A histogram based on the difference between average and measured deflection then shows that the tip deflection measurement has a precision $(1 \sigma)$ of $\sim 3 \mathrm{~nm}$, see Figure 9. This is good considering the surface roughness of $45 \mathrm{~nm}$ and the 10-nm RMS repeatability of the confocal profilometry. The measurement has been repeated for several similar beams, all revealing similar results.

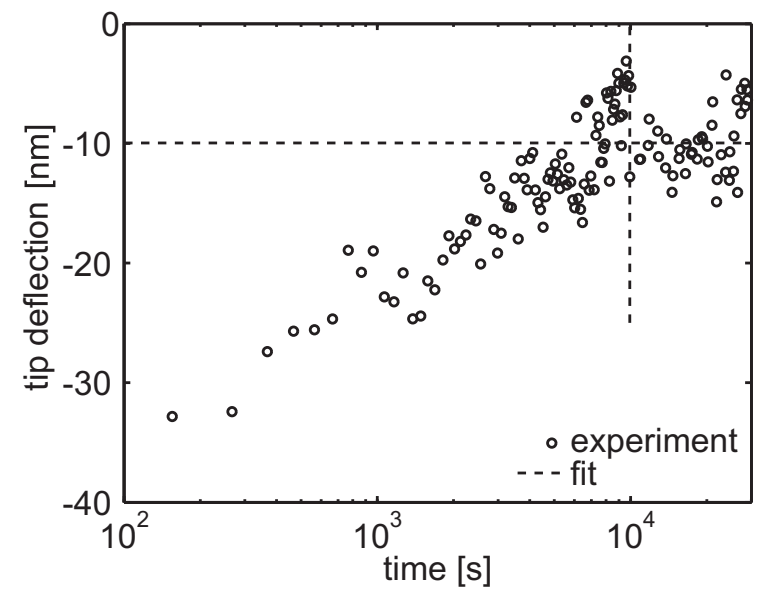

Figure 8: The displacement of the tip versus the logarithm of time. A fit (dashed line) is made for the time segment from 10.000-25.000 seconds.

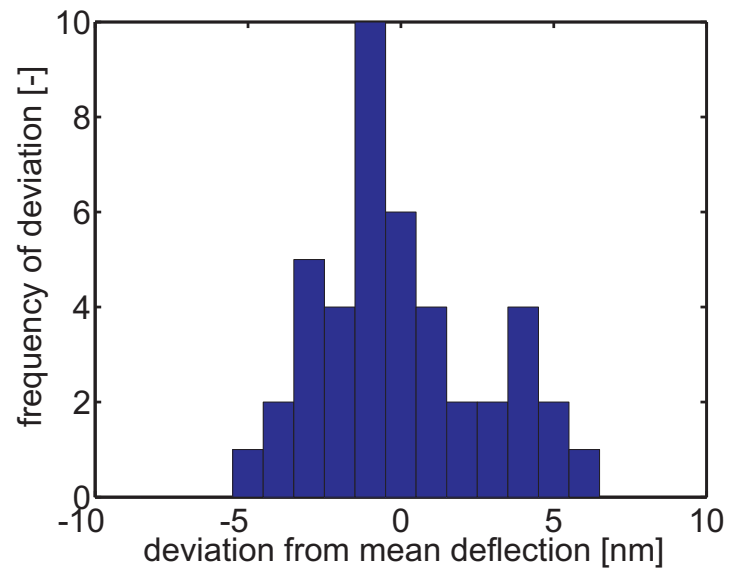

Figure 9: Histogram based on the data of the last 10000-25000 seconds to evaluate the precision of the measurement. From this a standard deviation in the tip deflection measurement of $\sim 3$ nm can be estimated.

\section{Analysis of experimental errors}

There are a few factors that cause errors in the measurement. First is the assumption that the deformation of the double clamped plate is negligible, thus effectively forming a fixed clamped end of the beam and being a suitable reference surface for tilt correction. Next the image correlation algorithm can introduce a statistical error as it has only pixel resolution: images cannot be correlated to sub-pixel precision. Furthermore temperature influences can also cause errors, especially at this scale. These potential factors of error are analyzed in more detail. 
The assumption of the negligible deformation of the double clamped plate is analysed by finite element analysis (FEA). A linear elastic model can be employed as the stress is largest during the elastic response; stress relaxation will only cause smaller deformations then modelled. The model consists of 3D, 8-node, first order, iso-parametric elements and is simulated in MarcMentat. In Figure 10, the finite element model is shown. Only half of the structure is modelled due to symmetry. To carefully simulate the experimental geometry (Figure 4), the clamped plate $(\sim 130 \mu \mathrm{m}$ long) is completely modeled together with the anchors, to which the boundary conditions of fixed displacements are actually applied.

In the simulation, a deflection of $100 \mathrm{~nm}$ is applied at the tip, corresponding to an upper limit on the deflection immediately after unloading. The resulting deformation of the plate is extracted from the simulation. It is shown in Figure 10 that towards the tip the plate deflects, whilst it is raised at the center. The increase in height is however limited to $0.5 \mathrm{~nm}$ at this center, whilst in the regions selected for leveling and height reference, it is $<0.1 \mathrm{~nm}$. Thus using the areas as indicated in Figure 10 for leveling and reference do not affect the overal precision.

To investigate the statistical error due to the image correlation step, a random topography is investigated where this topography is shifted with one pixel in every direction with respect to its original position. Then profiles are obtained the same way as described in paragraph 3 . The height uncertainty, due to the statistical error made in the image correlation step, on the evaluation of the deflection of the tip is depicted in Figure 11. The maximum error is identified as $\sim 1 \mathrm{~nm}$.

Lastly the errors due to temperature fluctuations are investigated. Fluctuations in laboratory temperature are $\pm 1.0^{\circ} \mathrm{C}$. Because the plate surface is used as reference height during the tip deflection recovery measurement, the thermal loop is effectivey constrained to the Al-beam in horizontal and vertical direction. Thus thermal expansion can be neglected during the unloading part of the experiment. However, the knife edge and beam are in contact during loading. The thermal loop now consists of the steel clamp, the silicon substrate, the alumunium and some thin film insulators. The steel and silicon comprise the bulk of the dimensions so the other materials are neglected. The difference in thermal expansion of stainless steel and silicon may result in a fluctuation in horizontal and vertical dimensions affecting the deflection during loading by $\sim 10 \mathrm{~nm}$ for temperature fluctuations of $\pm 1.0{ }^{\circ} \mathrm{C}$. Such a fluctuation can be neglected during loading of $\sim 800 \mathrm{~nm}$.

The evaluation has shown that the obtained precision of this method is reliable. Even more, a strong benefit is shown by the thermal insensitivity of the experimental setup. With carefull selection of materials and geometry of the micro-clamp differences in thermal expansion can be further reduced, greatly facilitating conducting experiments at elevated temperatures which will be reported in a future publication.

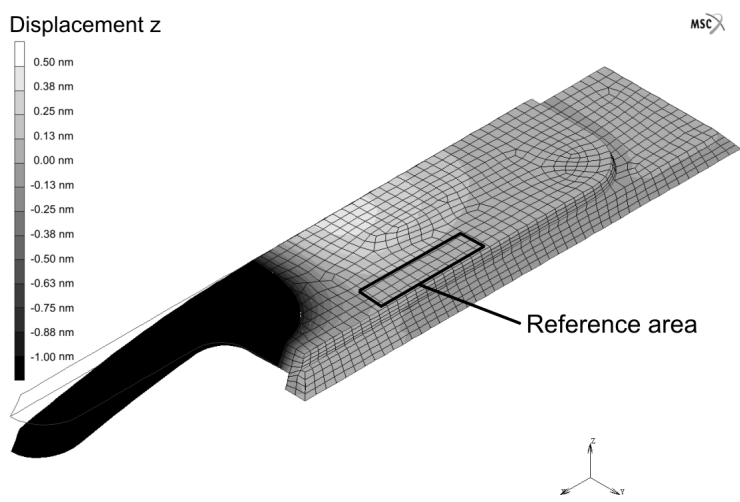

Figure 10: Finite element simulation of the height deformation of the beam and the double clamped plate at 100 nm deflection of tip. The deformation is graphically exaggerated and the scale range is adjusted to visualize the small variations of the deformation of the plate. Black indicates deflection below a depth of $1 \mathrm{~nm}$. The model shows the plate is raised in the center by $0.5 \mathrm{~nm}$. The height of the area's selected for reference height and leveling remains within a height of 0-0.1 nm.

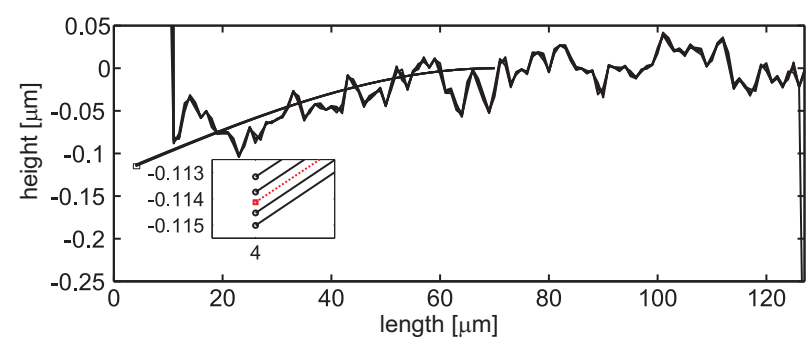

Figure 11: The influence of an erroneous xy-correlation on the overall profile fit is shown. The topography is shifted 1 pixel in the horizontal and vertical direction to imitate the possible deviation introduced by the image correlation software. The inset shows a zoom around the original profile (dashed red line, center of five lines) and the profiles due to erroneous correlation, indicating an error of less than $1 \mathrm{~nm}$.

\section{Conclusions}

An experimental methodology is presented together with measurement results to measure time-dependent deformation in $\mu \mathrm{m}$-sized free-standing aluminum-copper alloy cantilever beams. As a first result the deformation recovery of a beam is measured over a period of $\sim 6$ hours, showing a recovery of $20 \mathrm{~nm}$ during this period after initial spring back. A permanent deflection of $\sim 10 \mathrm{~nm}$ is observed. The precision $(1 \sigma)$ is $\sim 3 \mathrm{~nm}$, which is good considering the relatively high surface roughness and unavoidable experimental limitations.

The measurement is possible due to the design of the experiment: measuring time-dependent recovery with confocal profilometry in a simple mechanical setup with minimal sample handling. A micro-clamp deflects onchip micro-beams to a depth that can be controlled with $\sim 50 \mathrm{~nm}$ precision (but can be measured again with $\sim 3 \mathrm{~nm}$ precision). The main factors influencing the precision are image correlation errors and deformation of reference surfaces. At the same time, the methodology is insensitive 
to thermal fluctuations. Analysis of these factors show that the precision of $\sim 3 \mathrm{~nm}$ is reliable.

The next step in this research is to apply timedependent material models incorporated into FEA to extract physically meaningfull parameters, the procedure of which will be published in the future. With this full methodology in place, grain size and grain orientation effects can be probed by coupling measured differences in grain size and grain orientation distributions between different microbeams of the same geometry (on the same wafer) to changes in the observed creep behavior. Furthermore, experiments can be conducted at various temperatures to accelerate or probe different creep mechanisms. Ultimately device structural dimensions will be varied to probe more size-effects in creep of these structures.

\section{Acknowledgments}

Dr.Ir. Marcel van Gils and Ir. Jeroen Bielen at Netherlands B.V. are greatly acknowledged for their cooporation, support and fruitfull discussions in this work. This research is carried out under proj. nr. M62.2.08SDMP12 in the framework of the Research Program of the Materials Innovation Institute M2I and the Foundation for Fundamental Research on Matter (FOM) which is financially supported by the Netherlands Organization for Scientific Research (NWO).

\section{References}

1. W. M. Van Spengen, "MEMS reliability from a failure mechanisms perspective," Microelectron. Reliab., vol. 43, no. 7, pp. 1049-1060, 2003.

2. M. Van Gils, J. Bielen, and G. McDonald, "Evaluation of creep in RF MEMS devices," EuroSime 2007: Int. Conf. Thermal, Mechanical and Multi-Physics Simulation Experiments in Microelectronics and Micro-Systems, 2007 London: 2007.

3. Douglas, M. R., "Lifetime estimates and unique failure mechanisms for a Digital Micromirror Device," 1998, pp. 9-16.

4. G. Dehm, C. Motz, C. Scheu, H. Clemens, P. H. Mayrhofer, and C. Mitterer, "Mechanical sizeeffects in miniaturized and bulk materials," $A d v$. Eng. Mater., vol. 8, no. 11, pp. 1033-1045, 2006.

5. E. Arzt, "Size effects in materials due to microstructural and dimensional constraints: A comparative review," Acta Mater., vol. 46, no. 16, pp. 5611-5626, 1998.

6. T. Connolley, P. E. Mchugh, and M. Bruzzi, "A review of deformation and fatigue of metals at small size scales," Fatigue Fract. Eng Mater. Struct., vol. 28, no. 12, pp. 1119-1152, 2005.

7. R. Modlinski, A. Witvrouw, P. Ratchev, R. Puers, J. M. J. Den Toonder, and I. De Wolf, "Creep characterization of al alloy thin films for use in mems applications," Microelectron. Eng, vol. 76, no. 1-4, pp. 272-278, 2004.
8. R. Modlinski, P. Ratchev, A. Witvrouw, R. Puers, and I. D. Wolf, "Creep-resistant aluminum alloys for use in MEMS," J. Micromech. Microengineering, vol. 15, no. 7, p. S165-S170, 2005.

9. K. J. Hemker and W. N. Sharpe Jr, "Microscale characterization of mechanical properties," Annual Review of Materials Research, vol. 37, pp. 92-126, 2007.

10. N. K. R. Delhey, "An experimental methodology to characterize time-dependent deformation in freestanding aluminium thin-films." Master's Thesis , Eindhoven University of Technology, 2009.

11. J. Bielen, J. Stulemeijer, D. Ganjoo, D. Ostergaard, and S. Noijen, "Fluid-electrostatic-mechanical modeling of the dynamic response of RF-MEMS capacitive switches," EuroSime 2008: Int. Conf. Thermal, Mechanical and Multi-Physics Simulation Experiments in Microelectronics and Micro-Systems, 2008 Freiburg im Breisgau: 2008. 